\title{
Fontes Protéicas Suplementadas com Aminoácidos e Minerais para a Tilápia do Nilo Durante a Reversão Sexual
}

\author{
Fábio Meurer ${ }^{1}$, Carmino Hayashi ${ }^{2}$, Wilson Rogério Boscolo ${ }^{3}$, Christiano Rodrigues Schamber ${ }^{4}$, \\ Robie Allan Bombardelli ${ }^{5}$
}

\begin{abstract}
RESUMO - Objetivou-se, no presente experimento, comparar o efeito da origem da fonte protéica e da suplementação com lisina e metionina ou cálcio e fósforo para a tilápia do Nilo (Oreochromis niloticus), durante a reversão sexual. Foram utilizadas 200 larvas, distribuídas em 20 aquários de 12 litros, em um delineamento inteiramente casualizado em quatro tratamentos e cinco repetições. A temperatura pela manhã e à tarde, o oxigênio dissolvido, $\mathrm{pH}$ e condutividade elétrica da água foram, respectivamente, de $22,6 \pm 0,1^{\circ} \mathrm{C}$, $24,1 \pm 0,4^{\circ} \mathrm{C} ; 6,77 \pm 0,38 \mathrm{mg} / \mathrm{L}, 7,75 \pm 0,16 ;$ e $173,4 \pm 2 \mathrm{mS} / \mathrm{m}$. Os tratamentos foram compostos por quatro rações isoprotéicas e isoenergéticas: uma somente com ingredientes de origem animal (FA); outra com ingredientes de origem vegetal (FV) e duas com ingredientes de origem vegetal, uma com adição dos aminoácidos lisina e metionina (FAA) e outra com cálcio e fósforo (FP). Os valores médios finais de peso e comprimento dos animais submetidos à ração FA foi superior aos demais tratamentos, seguido pelo FP e FV, que não diferiram da FAA. O tratamento FA apresentou os maior valores de biomassa final, seguido do FP e FAA, que foram semelhantes ao FV. O fator de condição dos peixes do tratamento FA foi superior aos FAA e FV, porém o FP foi semelhante aos demais. A sobrevivência dos tratamentos FA, FV e FP foram semelhantes entre si e superiores ao FAA. Para a fase de reversão sexual da tilápia do Nilo, rações formuladas com ingredientes de origem animal foram mais eficientes que as formuladas com ingredientes de origem vegetal, mesmo quando estas foram suplementadas com lisina e metionina ou cálcio e fósforo.
\end{abstract}

Palavras-chave: fonte protéica, larvicultura, reversão sexual, suplementação, tilápia

\section{Protein Sources Supplemented with Amino Acids and Minerals to Nile Tilapia during Sex Reversal Phase}

\begin{abstract}
This work aimed to evaluate the effect of protein source origin and lysine and methionine or phosphorus and calcium supplementation to Nile tilapia during sex reversal phase. Two hundred fries were assigned to a completely randomized design with four treatments and five replications, in twenty $12 \mathrm{~L}$ aquarium. One aquarium with $10 \mathrm{Nile}$ tilapia fry was considered an experimental unit. Morning and afternoon temperatures, dissolved oxygen, $\mathrm{pH}$ and electric conductivity was $22.6 \pm 0.1^{\circ} \mathrm{C}, 24.1 \pm 0.4{ }^{\circ} \mathrm{C} ; 6.77 \pm 0.38 \mathrm{mg} /$ $\mathrm{L}, 7.75 \pm 0.16$ e $173.4 \pm 2 \mu \mathrm{S} / \mathrm{m}$, respectively. The treatments were diets, one only with protein source of animal origin (FA), other only with protein source plant origin (FV), another with protein source plant origin but supplemented with lysine and methionine (FAA) and other with protein source plant origin but supplemented with calcium and phosphorus (FP). Means of end values of weight and length fry submitted to FA diet was greater than others treatments, followed to FP and FV diets, who had same value that the FAA diet. FA diet showed higher values of final biomass, followed by FP and FAA, that showed the same value of FV diet. Fry condiction of FA diet was greater than FAA and FV, but similar to FP diet. The survival of FA, FV, and FP diets was same and greater than FAA. Diets with animal protein ingredients were more efficient than vegetal protein ingredients with lysine and methionine or calcium and phosphorus supplementation, for Nile tilapia during sex reversion phase.
\end{abstract}

Key Words: fry, protein source, sexual reversion, supplementation, tilapia

\section{Introdução}

A larvicultura e alevinagem de peixes são descritas como a fase que compreende desde a eclosão dos ovos até o alevino de tamanho comercial, período que, entre outros, varia em função da espécie, temperatura, nutrição. É uma das fases mais importantes dentro da exploração racional piscícola, pois, conforme Hayashietal. (2002), éresponsável pela obtenção de animais em quantidade e de qualidade, para as fases posteriores de criação.

\footnotetext{
${ }^{1}$ Zootecnista, MSc., Professor Assistente dos cursos de Medicina Veterinária, Agromonia e Biologia da Pontifícia Universidade Católica do Paraná (PUCPR) - Campus de Toledo; Av. da União, 500 - CEP: 85902-532-Toledo-PR; Doutorando PPZ-UEM (fabio.meurer@pucpr.br)

2 Pesquisador do Centro Avançado de Pesquisa Tecnológica do Agronegócio de Pescado Continental, APTA/SAA, São José do Rio Preto, SP(hayashi@pesca.sp.gov.br). Pesquisador do CNPq.

3 Zootecnista, Dr., Prof. de Engenharia de Pesca/UNIOESTE.

${ }^{4}$ Acadêmico de Biologia - UEM.

5 Engenheiro de Pesca, Msc., Prof. de Engenharia de Pesca/UNIOESTE, doutorando PPZ-UEM.
} 
Dentro da tilapicultura, a fase de larvicultura é, geralmente, denominada fase de reversão sexual, pelo processo a que estes indivíduos são submetidos neste período. A reversão sexual é de fundamental importância para o cultivo racional da tilápia do Nilo, em função da necessidade de obtenção de indivíduos machos para a engorda, evitando problemas provenientes dos gastos energéticos com a cópula e desova, excesso populacional nos viveiros e nesta espécie, o macho cresce mais que a fêmea.

Uma das características das rações comerciais encontradas para a fase de reversão sexual das tilápias são os altos teores de proteína bruta, que podem alcançar índices maiores que 50\%. Caracterizam-se por alta porcentagem de ingredientes de origem animal, que podem levar à maior quantidade de matéria mineral e, conseqüentemente, níveis de cálcio e de fósforo.

As fontes protéicas de origem vegetal são mais baratas que as de origem animal, porém apresentam balanço aminoacídico inadequado ao requerimento dos peixes (El-Dahhar \& El-Shazly, 1993), além da presença dos polissacarídeos não-amiláceos que podem influir de forma negativa no desempenho dos mesmos (Meurer \& Hayashi, 2003). Porém, a tilápia do Nilo pode, a partir da fase de alevino utilizar fontes protéicas de origem vegetal, como fonte única de proteína, sem problemas relacionados ao desempenho (Boscolo et al., 2001; Meurer, 2002).

Fontes protéicas de origem vegetal são geralmente preteridas na formulação de rações para a fase de reversão sexual da tilápia, em relação às de origem animal. Na literatura especializada, faltam dados sobre a possibilidade de inclusão dos mesmos nestas dietas.

Este trabalho foi conduzido com o objetivo de comparar o efeito da suplementação dos aminoácidos lisina, metionina e dos minerais cálcio e fósforo em rações à base de ingredientes de origem vegetal, com uma ração com ingredientes de origem animal e uma à base de ingredientes de origem vegetal. Avaliou-se o desempenho produtivo dos animais medidos a partir dos valores de peso final médio, comprimento final médio, biomassa total final, sobrevivência e condição corporal de larvas de tilápia do Nilo, durante a fase de reversão sexual.

\section{Materiais e Métodos}

O presente experimento foi realizado no Laboratório de Aqüicultura, do Departamento de Biologia na Universidade Estadual de Maringá, durante o período de 12 de março a 10 de abril de 2001. Duzentas larvas de tilápia do Nilo (Oreochromis niloticus), com dois dias de idade, foram distribuídas em delineamento experimental inteiramente casualizado, com quatro tratamentos e cinco repetições, em 20 aquários com $12 \mathrm{~L}$ de volume útil, sendo considerado, como unidade experimental, um aquário com 10 larvas.

Os aquários foram dotados de aeração contínua por pedras microporosas ligadas por meio de uma tubulação de PVC, a um compressor de ar, e foram sifonados para retirada das fezes e restos de ração, duas vezes ao dia, pela manhã (7h) e à tarde (14h30), com remoção de aproximadamente $10 \%$ da água nos primeiros dez dias, $20 \%$ até o vigésimo dia e $30 \%$ até final do período experimental. A temperatura da água foi aferida diariamente pela manhã e à tarde e os outros parâmetros ( $\mathrm{pH}$, oxigênio dissolvido e condutividade elétrica da água), quantificados semanalmente pela manhã sempre antes da limpeza dos aquários.

Quatro diferentes rações experimentais (Tabela 1) foram formuladas de acordo com as exigências para a tilápia do Nilo durante a reversão sexual, de 38,6\% de proteína digestível e $3.800 \mathrm{kcal} / \mathrm{kg}$ de energia digestível (Hayashi et al., 2002). Na Tabela 2, encontram-se os valores percentuais dos aminoácidos essenciais das rações experimentais, bem como as necessidades nutricionais dos aminoácidos para juvenis desta espécie.

Os tratamentos foram constituídos de quatro diferentes rações isoprotéicas e isoenergéticas: uma formulada apenas com fontes protéicas de origem animal (farinhas de peixe e de vísceras de aves) (FA); a segunda apenas com fontes protéicas de origem vegetal (farelo de soja e glúten de milho) (FV); outra semelhante à $\mathrm{FV}$, porém com inclusão de lisina e metionina, para que ficasse isoaminoacídica para lisina e metionina + cistina com a FA; e a última também semelhante à $\mathrm{FV}$, porém com inclusão de cálcio e fósforo, de maneira que permanecesse isocálcica e isofosfórica em relação à FA. O fornecimento das rações foi à vontade, na forma farelada (Meurer et al., 2003a), cinco vezes ao dia (8h, 10h30, 13h30, 15h30 e 17h30).

Para elaboração das rações, os ingredientes foram triturados em peneira de $0,5 \mathrm{~mm}$. Em razão da alta concentração de gordura nas farinhas de vísceras e de peixe, antes da moagem, os alimentos foram peneirados manualmente, em malha de $0,5 \mathrm{~mm}$ e, em seguida, a fração retida foi moída e, posteriormente,

R. Bras. Zootec., v.34, n.1, p.1-6, 2005 
Tabela 1 - Composição das rações experimentais fornecidas às larvas de tilápia do Nilo (Oreochromis niloticus) Table 1 - Composition of the experimental diets fed to Nile tilapia (Oreochromis niloticus) fries

\begin{tabular}{|c|c|c|c|c|}
\hline \multirow{2}{*}{$\begin{array}{l}\text { Ingredientes }(\%) \\
\text { Ingredients }\end{array}$} & \multicolumn{4}{|c|}{ Fontes de proteína (Protein sources) } \\
\hline & $\begin{array}{l}\text { Animal } \\
\text { Animal }\end{array}$ & $\begin{array}{l}\text { Vegetal } \\
\text { Plant }\end{array}$ & $\begin{array}{c}\text { Vegetal }+ \text { aa } \\
\text { Plant }+a a\end{array}$ & $\begin{array}{l}\text { Vegetal }+\mathrm{Ca} \text { e } \mathrm{P} \\
\text { Plant }+C a \text { and } P\end{array}$ \\
\hline Farinha de peixe $^{1}$ (Fish meal) & 36,34 & - & - & - \\
\hline Farinha de vísceras ${ }^{1}$ (Poultry meal) & 35,00 & - & - & - \\
\hline Farelo de soja $^{2}$ (Soybean meal) & - & 37,64 & 35,00 & 38,28 \\
\hline Glúten de milho ${ }^{1}$ (Gluten meal) & - & 32,77 & 31,59 & 33,65 \\
\hline Milho $^{1}$ (Maize) & 20,55 & 18,23 & 17,37 & 6,51 \\
\hline Óleo de soja ${ }^{1}$ (Soybean oil) & 7,09 & 5,24 & 7,20 & 8,69 \\
\hline $\mathrm{L}$-lisina $\mathrm{HCl}(\text { Lysine })^{3}$ & - & - & 2,04 & - \\
\hline DL-metionina $99^{3}$ (DL methionine) & - & - & 0,62 & - \\
\hline Fosfato bicálcico ${ }^{3}$ (Dicalcium phosphate) & - & 2,80 & 2,92 & 6,89 \\
\hline Calcário 3 (Limestone) & - & 1,79 & 1,74 & 4,46 \\
\hline $\mathrm{Sal}^{3}$ (Salt) & - & 0,50 & 0,50 & 0,50 \\
\hline Suplemento mineral e vitamínico 4 & 1,00 & 1,00 & 1,00 & 1,00 \\
\hline \multicolumn{5}{|l|}{ Mineral and vitamin supplement } \\
\hline BHT & 0,02 & 0,02 & 0,02 & 0,02 \\
\hline \multicolumn{5}{|l|}{ Nutrientes (\%) (Nutrients) } \\
\hline Proteína digestível ${ }^{1,2}$ (Digestible protein) & 38,60 & 38,60 & 38,60 & 38,60 \\
\hline Proteína bruta ${ }^{1,2}$ (Crude protein) & 43,16 & 41,12 & 41,33 & 41,11 \\
\hline Energia digestível (kcal/kg) ${ }^{1,2}$ (Digestible energy) & 3800 & 3800 & 3800 & 3800 \\
\hline Amido $^{3}$ (Starch) & 12,74 & 20,89 & 19,84 & 13,83 \\
\hline Gordura $^{1,2,3}$ (Fat) & 21,33 & 8,08 & 9,88 & 11,04 \\
\hline Fibra $^{3}$ (Fiber) & 0,39 & 2,52 & 2,37 & 2,34 \\
\hline Lisina $^{3}$ (Lysine) & 2,95 & 1,45 & 2,95 & 1,45 \\
\hline Metionina+Cistina ${ }^{3}($ Methionine + cystine $)$ & 2,15 & 1,57 & 2,12 & 1,55 \\
\hline Cálcio $^{3}$ (Calcium) & 3,31 & 1,40 & 1,40 & 3,31 \\
\hline Fósforo ${ }^{3}$ (Phosphorus) & 1,64 & 0,90 & 0,90 & 1,64 \\
\hline Ácido linoléico ${ }^{3}$ (Linoleic acid) & 5,45 & 3,56 & 4,96 & 5,61 \\
\hline \multicolumn{5}{|c|}{$\begin{array}{l}1 \text { De acordo com Meurer et al (2003b), para farinha de vísceras, farinha de peixe e glúten de milho. } \\
2 \text { De acordo com os dados de Boscolo et al. (2002), para farelo de soja, milho e óleo de soja. } \\
{ }^{3} \text { De acordo com os dados de Rostagno et al. (2000). } \\
{ }^{1} \text { According to data from Meurer et al. (2003b) for poultry by-products meal, fish meal, and gluten meal. } \\
{ }^{2} \text { According to data from Boscolo et al. (2002) for soybean meal, maize, and soybean oil. } \\
{ }^{3} \text { According to data from Rostagno et al. (2000). } \\
{ }^{4} \text { Níveis de garantia por quilograma do produto: Vit. A,1.200.000Ul; Vit. D3, } 200.000 \mathrm{UI} \text {; Vit. E, } 12.000 \mathrm{mg} \text {; Vit. K3, } 2.400 \mathrm{mg} \text {; Vit. B1, } \\
\text { 4.800 mg; Vit. B2, } 4.800 \mathrm{mg} \text {; Vit. B6, } 4.000 \mathrm{mg} \text {; Vit. B12, } 4.800 \mathrm{mg} \text {; Ác. Fólico, } 1.200 \mathrm{mg} ; \text { Pantotenato Ca, } 12.000 \mathrm{mg} \text {; Vit. C, } 48.000 \mathrm{mg} \text {; } \\
\text { Biotina, } 48 \mathrm{mg} \text {; Colina, } 65.000 \mathrm{mg} \text {; Niacina, } 24.000 \mathrm{mg} ; \text { Fe, } 10.000 \mathrm{mg} \text {; Cu, } 6.000 \mathrm{mg} \text {; Mn, } 4.000 \mathrm{mg} \text {; Zn, } 6.000 \mathrm{mg} \text {; I, } 20 \mathrm{mg} \text {; Co, } 2 \mathrm{mg} \text {; } \\
\text { Se, } 20 \mathrm{mg} \text {. }\end{array}$} \\
\hline
\end{tabular}

Tabela 2 - Composição percentual em aminoácidos essenciais das rações experimentais fornecidas às larvas de tilápia do Nilo (Oreochromis niloticus) ${ }^{1}$ e a exigência percentual de aminoácidos essenciais da tilápia do Nilo ${ }^{2}$

Table 2 - Percent composition of essential aminoacid of experimental diets fed to Nile tilapia (Oreochromis niloticus) ${ }^{1}$ fries and aminoacid percent requirement fed to Nile tilapia ${ }^{2}$

\begin{tabular}{|c|c|c|c|c|c|}
\hline \multirow[t]{2}{*}{$\begin{array}{l}\text { Aminoácidos } \\
\text { Aminoacids }\end{array}$} & \multirow[t]{2}{*}{$\begin{array}{l}\text { Exigências } \\
\text { Requirements }\end{array}$} & \multicolumn{4}{|c|}{$\begin{array}{l}\text { Fontes de proteína } \\
\text { Protein sources }\end{array}$} \\
\hline & & $\begin{array}{l}\text { Animal } \\
\text { Animal }\end{array}$ & $\begin{array}{l}\text { Vegetal } \\
\text { Plant }\end{array}$ & $\begin{array}{l}\text { Vegetal+aa } \\
\text { Plant }+a a\end{array}$ & $\begin{array}{l}\text { Vegetal+Ca e P } \\
\text { Plant }+C a \text { and } P\end{array}$ \\
\hline Arginina (Arginine) & 1,18 & 2,95 & 1,96 & 1,85 & 1,95 \\
\hline Fenilalanina(Phenylalanine) & 1,05 & 1,95 & 2,23 & 2,12 & 2,24 \\
\hline Histidina(Histidine) & 0,48 & 0,85 & 0,91 & 0,86 & 0,89 \\
\hline Isoleucina (Isoleucine) & 0,87 & 2,05 & 1,69 & 1,59 & 1,69 \\
\hline Leucina (Leucine) & 0,95 & 3,58 & 4,98 & 4,75 & 4,97 \\
\hline Lisina (Lysine) & 1,43 & 2,29 & 1,42 & 2,93 & 1,42 \\
\hline Cistina (Cystine) & 0,15 & 1,29 & 0,82 & 0,79 & 0,81 \\
\hline Metionina (Methionine) & 0,75 & 0,86 & 0,75 & 1,33 & 0,74 \\
\hline Treonina (Threonine) & 1,05 & 1,98 & 1,42 & 1,35 & 1,41 \\
\hline Triptofano (Tryptophan) & 0,28 & 0,35 & 0,35 & 0,33 & 0,35 \\
\hline Valina(Valine) & 0,78 & 2,64 & 1,82 & 1,72 & 1,81 \\
\hline
\end{tabular}

${ }^{1}$ De acordo com os valores publicados por Rostagno et al. (2000) (According to data published by Rostagno et al., 2000).

2 De acordo com os dados do NRC (1993) (According to data from NRC, 1993).

R. Bras. Zootec., v.34, n.1, p.1-6, 2005 
misturada à fração anterior. Após homogeneização dos ingredientes das rações, foi feita a inclusão de hormônio masculinizante (17- $\alpha$-metil-testosterona) na quantidade de $60 \mathrm{mg} / \mathrm{kg}$ de ração.

Após o término do período experimental, os alevinos foram abatidos por imersão em água gelada (cerca de $2^{\circ} \mathrm{C}$ ), pesados e medidos individualmente para avaliação do peso final médio, comprimento final médio, biomassa final total e fator de condição (obtido pr intermédio da expressão $\mathrm{wt} / \mathrm{lt}^{3} \mathrm{x} 100$, sendo $\mathrm{wt}=$ peso total $\mathrm{e} \mathrm{lt}=$ comprimento total $)$.

\section{Resultados e Discussão}

Os resultados médios das variáveis físico-químicas da água e não diferiram $(\mathrm{P}>0,05)$ entre os tratamentos (Tabela 3). $\mathrm{O}$ pH, condutividade e oxigênio dissolvido mantiveram-se dentro dos padrões recomendados para a aquiicultura (Boyd, 1990; Sipaúba-Tavares, 1995). Entretanto, a temperatura média da manhã e da tarde permaneceu abaixo do recomendado por Popma $\&$ Phelps (1998) para o bom desempenho da espécie.

Os valores médios do peso final e comprimento final das larvas de tilápia do Nilo submetidas à ração com fonte protéica de origem animal foram superiores $(\mathrm{P}<0,05)$ aos demais tratamentos, seguido pelo tratamento que recebeu ração com ingredientes de origem vegetal com suplementação com cálcio e fósforo. O tratamento com fonte protéica de origem vegetal e sem suplementação apresentou o pior resultado para esta variável, entretanto, aquele com suplementação de lisina e metionina foi semelhante aos tratamentos anteriores.

Foi obtida maior $(\mathrm{P}<0,05)$ biomassa final no tratamento com a ração com fonte protéica de origem animal, seguido do tratamento em que os animais foram submetidos à ração com suplementação de cálcio e fósforo. As larvas submetidas a ração vegetal suplementada com lisina e metionina tiveram o pior desempenho quanto à biomassa final

$\mathrm{O}$ fator de condição dos peixes do tratamento com ração fabricada com ingredientes protéicos de origem animal, foi superior $(\mathrm{P}<0,05)$ aos tratamentos que receberam ração com ingredientes de origem vegetal suplementada com lisina e metionina e com a ração contendo fontes protéicas de origem vegetal sem suplementação. Porém o tratamento com ração formulada com ingredientes de origem vegetal com suplementação de cálcio e fósforo foi semelhante aos demais. A sobrevivência dos alevinos submetidos aos tratamentos com ração com fontes protéicas de origem animal, de origem vegetal sem suplementação e a suplementada com cálcio e fósforo foram semelhantes entre si e superiores $(\mathrm{P}<0,05)$ àquele obtido pelo tratamento com ração suplementada com aminoácidos.

Trabalhos envolvendo testes de alimentos para a tilápia do Nilo são bastante comuns para animais a partir da fase de alevino (Viola \& Arieli, 1983; ElSayed, 1999; Wu et al., 1999; Meurer et al., 2000; Boscolo et al., 2001), demonstrando a possibilidade de utilização de alimentos protéicos de origem vegetal desde que as exigências de aminoácidos essenciais tenham sido atendidas. Entretanto, para a fase de reversão sexual tornam-se bastante escassos (Furuya et al., 1997).

Souza et al. (2000), testando diferentes fontes protéicas de origem vegetal, como fonte de $50 \%$ da proteína de rações para a tilápia do Nilo, durante a reversão sexual e com base no desempenho. Concluiu-se que as melhores fontes protéicas, de origem vegetal, foram os farelos de soja, girassol e canola, ao

Tabela 3 - Parâmetros físico-químicos da água dos aquários experimentais Table 3 - Physical-chemical parameters of experimental aquaria water

\begin{tabular}{|c|c|c|c|c|c|}
\hline \multirow{2}{*}{$\begin{array}{l}\text { Parâmetros da água } \\
\text { Water parameters }\end{array}$} & \multicolumn{4}{|c|}{ Fontes de proteína (Protein sources) } & \multirow[t]{2}{*}{$\mathrm{CV}(\%)$} \\
\hline & $\begin{array}{c}\text { Animal } \\
\text { Animal }\end{array}$ & $\begin{array}{c}\text { Vegetal } \\
\text { Plant } \\
\end{array}$ & $\begin{array}{r}\text { Vegetal+aa } \\
\text { Plant }+a a \\
\end{array}$ & $\begin{array}{l}\text { Vegetal+Ca e } \mathrm{P} \\
\text { Plant }+C a \text { and } P\end{array}$ & \\
\hline $\begin{array}{l}\text { Temperatura da manhã } \\
\text { Temperature at morning }\end{array}$ & 22,8 & 22,8 & 22,8 & 22,8 & 0,13 \\
\hline $\begin{array}{l}\text { Temperatura da tarde } \\
\text { Temperature at afternoon }\end{array}$ & 24,1 & 24,1 & 24,2 & 24,2 & 0,29 \\
\hline $\begin{array}{l}\text { Oxigênio dissolvido } \\
\text { Dissolved oxygen }\end{array}$ & 6,72 & 6,78 & 6,87 & 6,73 & 3,9 \\
\hline $\begin{array}{l}\mathrm{pH} \\
\text { Condutividade elétrica } \\
\text { Electric conductivity }\end{array}$ & $\begin{array}{r}7,79 \\
173,44\end{array}$ & $\begin{array}{c}7,71 \\
172,7\end{array}$ & $\begin{array}{r}7,77 \\
173,86\end{array}$ & $\begin{array}{r}7,73 \\
173,54\end{array}$ & $\begin{array}{l}1,14 \\
1,19\end{array}$ \\
\hline
\end{tabular}

R. Bras. Zootec., v.34, n.1, p.1-6, 2005 
Tabela 4 - Valores médios dos parâmetros finais de desempenho e sobrevivência da tilápia do Nilo (Oreochromis niloticus), durante a fase de reversão sexual, submetidas às rações experimentais

Table 4 - Average values of final parameters of performance and survival of Nile tilapia (Oreochromis niloticus), during the sex reversion phase, submitted to the experimental diets

\begin{tabular}{lcccc}
\hline Variáveis & \multicolumn{4}{c}{ Fontes de proteína } \\
& \multicolumn{4}{c}{ Protein sources } \\
\cline { 2 - 5 } Variables & Animal & Vegetal & Vegetal+aa & Vegetal+Ca e P \\
& Animal & Plant & Plant + aa & Plant + Ca and P \\
\hline Peso (Weight) $(\mathrm{g})$ & $0,2981 \mathrm{~A}$ & $0,1445 \mathrm{C}$ & $0,1756 \mathrm{BC}$ & $0,2150 \mathrm{~B}$ \\
Comprimento(Length) $(\mathrm{cm})$ & $2,48 \mathrm{~A}$ & $2,07 \mathrm{C}$ & $2,18 \mathrm{BC}$ & $2,30 \mathrm{~B}$ \\
Biomassa (Biomass) $(\mathrm{g})$ & $2,68 \mathrm{~A}$ & $1,36 \mathrm{BC}$ & $1,23 \mathrm{C}$ & $1,89 \mathrm{~B}$ \\
Fator de condição (Condition factor) & $1,99 \mathrm{~A}$ & $1,54 \mathrm{~B}$ & $1,54 \mathrm{~B}$ & $1,75 \mathrm{AB}$ \\
Sobrevivência (Survival) $(\%)$ & $90 \mathrm{~A}$ & $94 \mathrm{~A}$ & $70 \mathrm{~B}$ & 40,67 \\
\hline
\end{tabular}

Números na mesma linha acompanhados de letras diferentes diferem $(P<0,05)$ pelo teste Tukey.

Numbers in the same line followed by differences character was different $(P<.05)$ by Tukey test .

contrário do farelo de algodão que diminuiu o desempenho dos animais.

No presente experimento, as tilápias em fase de reversão sexual, alimentadas com ração contendo proteína de origem animal, apresentaram desempenho superior em relação aos outros tratamentos que utilizaram fontes protéicas de origem vegetal, mesmo quando suplementados com aminoácidos essenciais ou com cálcio e fósforo. A suplementação da ração experimental com fontes protéicas de origem vegetal, com cálcio e fósforo, proporcionou melhor desempenho que a suplementação com os aminoácidos lisina e metionina, fato que demonstra a importância destes macrominerais (McDowell, 1992), para o desenvolvimento das pós-larvas.

Um dos fatores que possivelmente pode estar relacionado ao pequeno efeito da suplementação com aminoácidos essenciais é a relação da fonte destes com a forma da ração utilizada. Foram utilizadas fontes sintéticas de lisina e metionina (bastante solúveis na água) e fornecida ração na forma farelada, que aumenta a possibilidade de perda destes nutrientes. Baldisserotto (2002) afirma que peixes, tanto larvas quanto adultos, podem absorver proteínas intactas por pinocitose na porção posterior do intestino, portanto, a suplementação de aminoácidos livres não seria a melhor maneira de aumentar a absorção de proteínas ou complementar uma ração deficiente em determinado aminoácido.

Com relação à importância da fase de reversão sexual dentro do cultivo da tilápia do Nilo, ressalta-se a necessidade da execução de trabalhos envolvendo testes de alimentos para esta fase, em função da importância no contexto da piscicultura nacional, para melhorar a formulação das rações para larvas de tilápias.

\section{Conclusões}

Para a fase de reversão sexual da tilápia do Nilo, rações formuladas com ingredientes de origem animal foram mais eficientes que aquelas com base em ingredientes de origem vegetal, mesmo quando esta foi suplementada com lisina e metionina ou cálcio e fósforo.

\section{Literatura Citada}

BALDISSEROTTO, B. Fisiologia de peixes aplicada à piscicultura. Santa Maria: Universidade Federal de Santa Maria, 2002. 212p.

BOSCOLO, W.R.; HAYASHI, C.; MEURER, F. Digestibilidade aparente da energia e proteína bruta de alguns alimentos pela tilápia do Nilo (Oreochromis niloticus, L.). Revista Brasileira de Zootecnia, v.31, n.2, p.539-545, 2002.

BOSCOLO, W.R.; HAYASHI, C.; MEURER, F. et al. Farinhas de peixe, carne e ossos, vísceras e crisálida como atractantes em dietas para alevinos de tilápia do Nilo (Oreochromis niloticus). Revista Brasileira de Zootecnia, v.30, n.5, p.1397-1402, 2001.

BOYD, C. Water quality in ponds for aquaculture. London: Birmingham Publishing Co, 1990. 482p.

EL-DAHHAR, A.A.; EL-SHAZLY, K. Effect of essential amino acids (methionine and lysine) and treated oil in fish diet on growth performance and feed utilization of Nile tilapia, Tilapia nilotica (L.). Aquaculture and Fisheries Management, v.24, n.6, p.731-739, 1993.

EL-SAYED, A.F.M. Alternative dietary protein sources for farmed tilapia, Oreochromis spp. Aquaculture, v.179, p.149-168, 1999.

FURUYA, V.R.B.; HAYASHI, C.; FURUYA, W.M. Farelo de canola na alimentação da tilápia do Nilo (Oreochromis niloticus L), durante o período de reversão de sexo. Revista Brasileira de Zootecnia, v.26, n.6, p.1067-1073, 1997.

HAYASHI, C.; BOSCOLO, W.R.; SOARES, C.M. et al. Exigência de proteína digestível para larvas de tilápia do Nilo no período de reversão sexual. Revista Brasileira de Zootecnia, v.31, p.823-828, 2002.

McDOWELL, L.R. Minerals and animal and human nutrition. San Diego: Academic Press, 1992. 524p.

R. Bras. Zootec., v.34, n.1, p.1-6, 2005 
MEURER, F. Cultivo de tilápias. In: CONGRESSO PARANAENSE DOS ESTUDANTES DE ZOOTECNIA, 23., 2002, Maringá. Anais... Maringá: Universidade Estadual de Maringá, [2002a]. CD-ROM.

MEURER, F.; HAYASHI, C. Polissacarídeos não-amilásceos na nutrição de peixes - Revisão. Arquivos de Medicina Veterinária e Zoologia da Unipar, v.6, n.2., p.127-138, 2003.

MEURER, F.; HAYASHI, C.; BOSCOLO, W.R. Digestibilidade aparente de alguns alimentos protéicos pela tilápia do Nilo (Oreochromis niloticus). Revista Brasileira de Zootecnia, v.32, n.6, p.1801-1809, 2003b.

MEURER, F.; HAYASHI, C.; BOSCOLO, W.R. Influência do processamento da ração no desempenho e sobrevivência da tilápia do Nilo durante a reversão sexual. Revista Brasileira de Zootecnia, v.32, n.2, p.262-267, 2003a.

MEURER, F.; HAYASHI, C.; SOARES, C.M.; et al. Utilização de levedura spray dried na alimentação de alevinos de tilápia do Nilo (Oreochromis niloticus L.). Acta Scientiarum, v.22, n.2, p.479-484, 2000.

NATIONAL RESEARCH COUNCIL - NRC. Nutrient requeriments of fish. Washington: National Academy Press, 1993. 114p.

POPMA, T.J.; PHELPS, R.P. Status report to commercial tilápia producers on monosex fingerling productions techniques. In: SIMPÓSIO SUL AMERICANO DE AQUICULTURA, 1., 1998, Recife. Anais... Florianópolis: SIMBRAQ, 1998. p.127.
ROSTAGNO, H.S.; ALBINO, L.F.T.; DONZELE, J.L. et al. Tabelas brasileiras para aves e suínos: composição de alimentos e exigências nutricionais. 1.ed. Viçosa, MG: Universidade Federal de Viçosa, 2000. 141p.

SIPAÚBA-TAVARES, L.H.S. Limnologia aplicada à aquicultura. Jaboticabal: FINEP, 1995. 70p.

SOUZA, S.R.; HAYASHI, C.; GALDIOLI, E.M. et al. Diferentes fontes de protéicas de origem vegetal para a tilápia do Nilo, durante a reversão sexual. In: REUNIÃO ANUAL DA SOCIEDADE BRASILEIRA DE ZOOTECNIA, 37., 2000, Viçosa. Anais... Viçosa: SBZ/Gmosis, [2000]. CD-ROM.

UNIVERSIDADE FEDERAL DE VIÇOSA - UFV. SAEG Sistema para análises estatísticas e genéticas. Versão 7.1. Viçosa, MG. 150p. (Manual do usuário).

VIOLA, S.; ARIELI, Y. Evaluation of different grains as ingredients in complete feeds for carp and tilapia in intensive culture. Israel Journal Aquaculture, v.35, p.38-43, 1983.

WU, Y.V.; TUDOR, K.W.; BROWN, P.B. et al. Substitution of plant proteins or meat and bone meal in diets of Nile tilapia. North American Journal of Aquaculture, v.61, n.1, p.58-63, 1999.

Recebido em: 07/10/03

Aceito em: 16/08/04 